Journal of Qualitative Criminal Justice \& Criminology

\title{
Book Review | Life After Death Row: Exonerees' \\ Search for Community and Identity
}

Jeanne Subjack ${ }^{1}$

${ }^{1}$ Sam Houston State University

Published on: Apr 01, 2013

Updated on: Jul 12, 2020

DOI: $10.21428 / 88 \mathrm{de} 04 \mathrm{a} 1.20 \mathrm{a} 39 \mathrm{e} 21$

License: Creative Commons Attribution 4.0 International License (CC-BY 4.0). 
Saundra D. Westervelt \& Kimberly J. Cook. Life After Death Row: Exonerees' Search for Community and Identity. Rutgers University Press, 2012; 296 pp.; ISBN: 9780813553825.

Life After Death Row examines how individuals wrongly sentenced to death adjust to life after their release. The idea for the book arose in 2009, after Westervelt and Cook attended a conference and learned about the different aspects related to wrongful convictions that had yet to be addressed in academia. To gain a more thorough understanding of the events the participants experienced, the authors used life history and feminist methods to conduct their research. Although the current analysis is not necessarily focused on gender, feminist methods are useful here because they can be applied when a researcher "seeks an understanding of participants as whole people with often conflicting beliefs and feelings ..." (pp. 21-22). The authors are able to gain insight into some of the more complex relationships and issues that exist by combining this methodology as a supplemental tool for life history methods.

Westervelt and Cook divide their book into four sections. The first section begins by providing statistics regarding the changes in acknowledging the issue of wrongful convictions and immediately stress that numbers do not provide the entire picture. They also set up the parameters of their research by focusing on individuals who were exonerated based on actual innocence and were so identified by the Death Penalty Information Center (DPIC). The authors examined available news coverage for the individuals, conducted life-history interviews, and recorded field notes during their interactions with the participants. There was only one instance where the authors had to conduct their interviews via written correspondence, because the individual was in federal prison. They conducted face-to-face interviews with all the other participants.

Part One also provides a closer look at who the participants are including: how long they were on death row; if their case involved the use of DNA evidence; what year they were exonerated; and if they received any compensation. Geographically, 11 states were represented, some of which had multiple participants sentenced. The average time spent on death row was 9.5 years, and ranged from 2 to 26 years for the 18 individuals. Finally, DNA evidence was critical for the release of 3 of the participants (17\%), because this evidence was not available at the time of their original trials (Westervelt \& Cook, 2012).

Part Two looks at the issues the participants faced after their exonerations. Some of the issues include finding a place to live, maintaining steady employment, and rebuilding relationships with family and friends. The most basic issue exonerees face immediately after release is where to stay. Several individuals were only give a few hours' notice of their release and were unable to better prepare 
themselves. Other issues include facing the deaths of family and friends, as well as losing family members who still believe in their guilt.

Part Three examines how the individuals process their official status as innocent, both while in prison and after their release. For example, Chapter 8 addresses how the participants internalize their new status as former death row inmates. It is here that the stories seem to be dominated by particular participants, and while their voices certainly need to be heard, it appears the others do not have a story to share. It is unclear why certain individuals did not have responses, but it may simply be that such issues were not addressed as thoroughly in each interview. At such a point, it is important to remember the fact that qualitative research may take unexpected detours.

The other focus of Part Three includes compensation for the exonerees. Not only do exonerees need financial stability and recognition of the time they lost having careers and income, many also felt they needed formal recognition of their innocence. The issues outlined enhance the necessity of such a book, because these are voices largely unheard, and therefore many of these issues are unknown.

The final section focuses upon the exonerees' thoughts concerning what assistance should be provided upon release, particularly compensation and assistance in the way of employment and emotional support. Emphasis on compensation and related issues highlights the importance of addressing a topic like life after release qualitatively, because the depths of these issues largely go unnoticed in quantitative work. The final chapter, the epilogue, brings the book full circle. We met the exonerees at the beginning and learned about the situations that led to their sentencing. At the end, we learn about their lives currently, although their journey is far from over. Sabrina Butler was convicted in 1989 of the murder of her baby. Butler was 18 at the time and served $5^{1 / 2}$ years in prison, $2^{1 / 2}$ of which were on death row. At the time of the book's publication, Butler still lived in the same town in which she was convicted. She married and now has three children. She recently filed for compensation and was still waiting to receive it.

Overall, this book provides a unique perspective on the life of a death row exoneree, both while in prison and after release. Each particular issue they faced could potentially fit its own book, and the depth of every issue is difficult to grasp in a single chapter. None of the exonerees were from Texas, which is interesting because this state accounted for 37\% of total executions as of 2011 (Fins, 2009). While there may not be exonerees from Texas, based upon the number of individuals sentenced to death, it appears as though it is possible and could be addressed. Finally, the chapter focusing on the exonerees' emotional struggles, Chapter 5, seems brief, with many of the personal anecdotes coming from the same few individuals.

Despite these criticisms, this book provides an important insight into the world of death row exonerees, and many of the issues addressed would not be otherwise known. Criminal justice students 
in corrections classes would benefit from reading this book, because it raises some of the current issues in the prison system. Researchers interested in policy should also read this book. Based upon the research, it is clear that there needs to be reform related to not only sentencing policies, but also policies for post-release. Hopefully, this book will also inspire more research on this topic, particularly qualitative research. Such a harrowing experience requires personalized stories to spread awareness, because without them, numbers are irrelevant.

\section{References}

Fins, D. (2011). Death row U.S.A.: A quarterly report by the Criminal Justice Project of the NAACP Legal Defense and Educational Fund, Inc. Retrieved from http://www.naacpldf.org/files/publications/ DRUSA_Winter_2011.pdf 